\title{
Specific language impairment: speech perception in relation to noise
}

\author{
Trandil H. Elmahallawi ${ }^{1}$, Takwa A. Gabr ${ }^{2^{*}}$ (D), Mohamad E. Darwish ${ }^{3}$ and Fatma M. Seleem ${ }^{1}$
}

\begin{abstract}
Background: Children with specific language impairment (SLI) fail to develop age-appropriate language despite being apparently normal in other respects. Those children usually have abnormal speech perception in noise. This work is designed to investigate speech perception in background noise in those children. It included two groups of children: control group ( 15 children with normal typical language development) and study group ( 25 children diagnosed with SLI). All children were submitted to intelligence scale, language assessment, full audiological evaluation, and Arabic Pediatric Speech Intelligibility in noise test (PSI).

Results: Results showed no statically significant difference in total and verbal $I Q$, while non-verbal IQ was significantly lower in the study group. As regard results of speech audiometry, the control group had better SRT and higher WD\% than the study group. Expressive, receptive, and total language scores were lower in the study group. Arabic Pediatric Speech Intelligibility in noise test showed significantly increased PSI scores with increasing the SNR from 0 to $+8 \mathrm{~dB}$ in both groups. The comparison between both groups showed a significant higher score in the control group at different $\mathrm{S} / \mathrm{N}$ recording conditions.
\end{abstract}

Conclusions: Children with SLI have difficulty in speech perception when compared to typically developed language children. This difficulty is more apparent in the presence of background noise.

Keywords: Specific language impairment (SLI), Pediatric Speech Intelligibility (PSI), Speech perception

\section{Background}

Specific language impairment (SLI) is a developmental disorder that results in functional communication impairment [1]. It refers to children who fail to develop age-appropriate language despite being apparently having normal hearing, intelligence, cognition, and neurological development; however, they talk relatively late. Diagnosis of SLI is generally dependent on the exclusion criteria of absence of neurological or psychiatric impairments. They also have normal hearing and vision, and a nonverbal (performance) IQ above 85. Those children have lower language age than excepted from their chronological age, and they exhibit deficits in phonology, morphology, and syntax [2].

\footnotetext{
*Correspondence: takwagabr@gmail.com; takwagabr@med.kfs.edu.eg ${ }^{2}$ Audiovestibular Unit, Otolaryngology Head and Neck Surgery Department, Kafrelsheikh University Hospitals, El-Geish street, Kafrelsheikh 33516, Egypt Full list of author information is available at the end of the article
}

Several cause factors might be related to SLI including genetic cause supported by the presence of family history in several studies ranging from 24 to $77 \%[3,4]$. Prenatal and perinatal exposure to tobacco, chemicals, or disease might be risk factor for SLI [5]. Neurological disorders such as reduced cerebral volume and atypical pattern of cerebral asymmetry which involve perisylvian, frontal, and parietal regions might be contibuting to the development of SLI [6].

Specific language impairment is a very heterogeneous disorder, and it includes expressive and receptive phonological and phonetic deficits, reduced vocabulary, or difficulties producing coherent texts [7]. Abnormal neural encoding of auditory information appears to play a major role in the disruption of normal language skills. This could be related to an impaired perception of acoustic cues in speech signals [8]. 


\section{Aims of the work}

This study is designed to investigate, through psychophysical evaluation, how the speech sounds are perceived in those children with SLI in quiet and in the presence of noise and whether encoding of the speech is disrupted in these children or not.

\section{Method}

In this work, we recruited 40 children to participate divided into two groups: control group (group I) consisted of 15 children with normal typical language development and study group (group II) consisted of 25 children diagnosed with specific language impairment.

Children of the study group were evaluated by a speech-language consultant. Their diagnostic criteria included below-average language skills as expected for the child's age, low language abilities that interfere with the child's ability to communicate effectively with other people, the expressive language showed non-specific words, and short simple sentences to express meanings beyond the age at which children may be using more complex language in addition to difficulty in understanding of receptive language [9].

Children of both groups' age range was 3-6 years. All children have bilateral normal peripheral hearing $(\leq 15$ $\mathrm{dB}$ along the frequency range of $250-8000 \mathrm{~Hz}$ ) and bilateral normal middle ear function, average or above average IQ (>85) intelligence, and normal speech and language development as reported by parent and evidenced by modified Preschool Language Scale (PLS-4) $[10]$ in group I.

\section{Exclusion criteria}

Children with family history of hearing loss, children with hearing loss or middle ear disorders, children with behavioral disorders, low IQ, and uncooperative children. This study was done at the Audiovestibular Medicine Unit, at Tanta University. The scientific research committee approved this thesis by approval code 30166/ $3 / 31$.

Children of both groups were submitted to the following:

- Basic audiological evaluation [pure tone audiometry, speech audiometry (GSI 61 audiometer, USA), immittancemetry (Interacoustic AT235h, Denmark)].

- Intelligence scale: using the Arabic version of the 5th edition of Stanford-Binet [10] standardized by Faraj et al. [11]. This test covers age range from 2 up to 24 years and taps the following: short-term memory, spatial orientation and numerical concepts, and language skills
- Language assessment using modified PLS-4 test [10]. Expressive language, receptive language, and total language scores were calculated.

- Pediatric Speech Intelligibility in noise test (PSI):

The child was seated in the sound-treated room and parent seated next to him/her to make child more comfortable. Twenty sentences of meaningful Arabic sentences within the vocabulary level of children were presented via headphones in the presence of multi-talker babbles. Before formal testing, the child was trained to the test procedure through training session (in quiet) and instructed to ignore the multi-talker babbles and concentrate on the speech sentences and repeat them. During the formal test, 10 different sentences were present monaurally at 40dBSL (re: SRT), and signal-tonoise ratio (SNR) was $0,4 \mathrm{~dB}$, and $8 \mathrm{~dB}$. Scoring is calculated by counting the number of correctly identified key words in the sentence in the presence of multi-talker babbles at each SNR [11, 12]. According to this test, children fall into 5 categories: category 1 (10-29\%, unintelligible speech), category $2(30-50 \%$, poor intelligibility), category $3(51-66 \%$, fair intelligibility), category 4 (67-84\%, good intelligibility), and category $5(85-100 \%$, excellent intelligibility).

\section{Statistical analysis}

Both Student's $t$-test and Mann Whitney's test were used for comparison of quantitative variables between two groups of normally and abnormally distributed data respectively. ANOVA test was used for comparison of quantitative variables between more than two groups of normally distributed data with Tuckey test as post hoc test. Pearson correlation was used to show correlation between two continuous normally distributed variables. In all tests, $P$ value of $<0.05$ is considered statistically significant.

\section{Results}

This study included 40 children divided into two groups. The control group (GI) consisted of 15 children (4 males and 11 females). Their mean age was $5.04 \pm 0.79$ years with typical language development. The study group (GII) consisted of 25 children (19 males and 6 females). Their mean ages were $4.77 \pm 0.85$ years and diagnosed with specific language impairment. Children of both groups had bilateral normal peripheral hearing, bilateral type A tympanograms, and within normal ipsilateral and contralateral acoustic reflex thresholds.

Psychological evaluation was done for all children in both groups using the Arabic version of the 5th edition of Stanford-Binet [13] translated by Faraj et al. [11]. Results showed no statistically significant difference in total and verbal IQ, while non-verbal IQ was significantly 
lower in the study group when compared to control $(P<$ 0.05) (Table 1).

Results of PTA showed no statistically significant differences between right and left ears in each group. Comparison between groups also showed no statistically significant differences between both groups, and the PTA averages were $7.44 \pm 1.7 \mathrm{~dB}$ and $9.6 \pm 1.444 .26 \mathrm{~dB}$ in the right and left ears of the control group, whereas the PTA average in the study groups was $8 \pm 1.63$ and $9.7 \pm$ $1.78 \mathrm{~dB}$ in the right and left ears respectively. As regard results of speech audiometry, children of both groups showed normal SRTs in both the right and left ears with no significant difference; however, the control group had better SRT than the study group. The WD\% also showed significantly higher scores in the control group in both ears (Table 1).

Evaluation of expressive and receptive language was done using PLS-4 test [10]. In each group, there was no statistically significant differences between scores of both types of language tests. The comparison between both groups showed lower scores in the study group when compared to normal group for the expressive, receptive, and total language scores indicating language delay in the study groups at all levels (Table 1).

Arabic Pediatric Speech Intelligibility in noise test at different SNR of $0,+4$, and $+8 \mathrm{~dB}$ was done in each group. Results in the control and study groups showed no statistically significant differences between the right ear and left ears for different SNRs paradigm. In each group, there were significantly increased PSI scores with increasing the SNR from 0 to $+8 \mathrm{~dB}$ in both the right and left ears. The comparison between control and study groups showed significant higher scores in the control group at different SNR recording conditions. All participants were affected by noise, but the study group was more affected than control group (Table 2).

Spearman correlation was done between PSI scores and age. Results showed a statistically significant positive correlation between PSI at different SNR and age which was maximum at 0 SNR. Spearman correlation was also done between PSI and language test scores and revealed statistically significant positive correlation between PSI at different SNRs and language test score at 0 SNR. At other SNRs, only expressive language scores showed a positive correlation at 4 and 8 SNRs (Table 3).

\section{Discussion}

Specific language impairment has long-term adverse sequelae on language, learning, and behavior. Both groups of this study showed no significant difference as regard age; however, the study group showed high prevalence of SLI in male children (3:1). This agreed with many clinical data, for example, Dockrell and Lindsay [14] and EL-Amergy et al. [15].

All children of the study group had normal IQ. Similar results were reported by Bishop and McArthur [16] who reported that SLI children have normal IQ. However, the nonverbal IQ was significantly lower in the study group. This suggested the presence of independent causal pathways for verbal and nonverbal IQ outcomes, particularly in the domain of grammar [17]. In each group, the comparison of expressive and receptive language scores was done and revealed no statistically significant difference. However, the study group showed lower scores in the expressive, receptive, and total language when compared to normal group. This indicated language delay in the study groups at all levels. Brain imaging, behavioral, and neurophysiological studies showed that SLI is a neurodevelopmental disorder that is characterized by a disturbance in the dynamics of brain development. This in turn will affect the cortical and subcortical morphology in the brain regions that support language acquisition, learning, and memory and will be reflected as lower language processing skills [18-20].

In each group, there were no significant differences between the expressive and receptive language scores using

Table 1 Results of the language test in both groups. *P significance $<0.05$

\begin{tabular}{|c|c|c|c|c|c|}
\hline & & GI & GII & $t$-value & $P$-value \\
\hline Age & & $5.04 \pm 0.79$ & $4.77 \pm 0.85$ & 1.17 & 0.24 \\
\hline \multirow[t]{3}{*}{ IQ } & Total & $108.00 \pm 5.35$ & $106.96 \pm 7.16$ & 0.60 & 0.54 \\
\hline & Non-verbal & $109.93 \pm 7.03$ & $99.28 \pm 13.64$ & 3.53 & $0.001^{*}$ \\
\hline & Verbal & $97.93 \pm 8.96$ & $96.24 \pm 11.93$ & 0.60 & 0.55 \\
\hline \multirow[t]{3}{*}{ Language scores } & Expressive & $4.91 \pm .8$ & $4.11 \pm .93$ & 2.79 & $<0.009^{*}$ \\
\hline & Receptive & $5.2 \pm .83$ & $4.12 \pm .86$ & 3.52 & $<0.001^{*}$ \\
\hline & Total & $5.05 \pm .79$ & $4.11 \pm .95$ & 3.9 & $<0.001^{*}$ \\
\hline \multirow[t]{2}{*}{ SRT } & Right ear & $6.33 \pm 2.28$ & $10 \pm 2.5$ & 5.21 & $<0.001^{*}$ \\
\hline & Left ear & $7 \pm 2.53$ & $9.4 \pm 2.19$ & 3.04 & $<0.001^{*}$ \\
\hline \multirow[t]{2}{*}{ WD\% } & Right ear & $98.57 \pm 1.98$ & $84.48 \pm 4.9$ & 12.55 & $<0.001^{*}$ \\
\hline & Left ear & $99.14 \pm 1.8$ & $83.2 \pm 5$ & 14.43 & $<0.001^{*}$ \\
\hline
\end{tabular}


Table 2 Results of the PSI test in both groups. ${ }^{*} P$ significance $<0.05$

\begin{tabular}{|c|c|c|c|c|c|}
\hline & & GI & GII & $t$-value & $P$-value \\
\hline \multirow[t]{4}{*}{ Right } & $0 \mathrm{~dB}$ & $60.00 \pm 7.55$ & $14.80 \pm 7.70$ & 5.37 & $<0.001 *$ \\
\hline & +4 SNR & $75.33 \pm 7.43$ & $49.20 \pm 9.53$ & 9.07 & $<0.001 *$ \\
\hline & +8 SNR & $92.66 \pm 7.98$ & $68.00 \pm 8.16$ & 9.32 & $<0.001 *$ \\
\hline & \multicolumn{2}{|c|}{$\begin{array}{l}\boldsymbol{F}=68.22 \quad P<0.001 \\
\boldsymbol{P} \mathbf{1}<0.001 \quad P 2>0.001 \quad P 3>0.001\end{array}$} & $\begin{array}{l}\boldsymbol{F}=63.57^{*} P<0.001 \\
\boldsymbol{P} \mathbf{1}<0.001 \quad P 2>0.002 \quad P 3>0.001\end{array}$ & & \\
\hline \multirow[t]{4}{*}{ Left } & $0 \mathrm{~dB}$ & $56.66 \pm 9.75$ & $15.20 \pm 8.71$ & $5.34^{*}$ & $<0.001 *$ \\
\hline & +4 SNR & $73.33 \pm 6.17$ & $46.80 \pm 9.00$ & 10.06 & $<0.001 *$ \\
\hline & +8 SNR & $89.33 \pm 7.98$ & $67.20 \pm 7.91$ & 8.53 & $<0.001 *$ \\
\hline & \multicolumn{2}{|c|}{$\begin{array}{l}\boldsymbol{F}=62.27^{*} P<0.001 \\
\boldsymbol{P} \mathbf{1}<0.001 \quad P 2>0.002 \quad P 3>0.001\end{array}$} & $\begin{array}{l}\boldsymbol{F}=60.90 P<0.001 \\
\boldsymbol{P} \mathbf{1}<0.001 \quad P 2>0.002 \quad P 3>0.001\end{array}$ & & \\
\hline
\end{tabular}

PLS-4 test [10]. However, the comparison between both groups showed lower scores in the study group when compared to control for the expressive, receptive, and total language scores. This agreed with Dale et al. [21].

Results of PTA showed within normal results with no significant differences between both groups. Results of speech audiometry showed within normal results in both groups, however, with significant higher SRTs and lower SD\% scores in the study group in both the right and left ears. This might be related to deficits in sound context and inability to hear the acoustic distinction among successive brief speech sounds with subsequent difficulty in auditory perception [22]. Language-impaired children also have difficulty in creating complex semantic relationships within and between words, although their early lexical development matches that of children with normal typical language development [15].

Arabic Pediatric Speech Intelligibility in noise test was done at different SNR $(0,+4$, and $+8 \mathrm{~dB})$ in both groups. This test was designed to assess the selective auditory attention, auditory closure, cognitive, speech, and language abilities. In each group, both the right and left ears showed similar results at different SNRs with significantly increased PSI scores with increasing the SNR from 0 to $+8 \mathrm{~dB}$ in both ears in each group (Table 2). This emphasizes the previous notion that noise has a physiological and psychological impact on the individuals exposed to it. Generally, it interferes with the oral communication through its masking effect on speech sounds, in addition to its main effect of reducing hearing [23]. The

Table 3 Correlation results between PSI scores, age, and language tests. ${ }^{*}$ P significance $<0.05$

\begin{tabular}{|c|c|c|c|c|c|c|c|c|}
\hline \multirow[t]{3}{*}{ PSI } & \multirow{2}{*}{\multicolumn{2}{|c|}{ Age }} & \multicolumn{6}{|c|}{ Language tests } \\
\hline & & & \multicolumn{2}{|c|}{ Total } & \multicolumn{2}{|c|}{ Expressive } & \multicolumn{2}{|c|}{ Receptive } \\
\hline & $r$ & $P$ & $r$ & $P$ & $r$ & $P$ & $r$ & $P$ \\
\hline $0 \mathrm{~dB}$ & 0.53 & $<0.001$ & 0.61 & 0.001 & 0.68 & $<0.001$ & 0.61 & 0.001 \\
\hline +4 SNR & 0.31 & 0.02 & 0.37 & 0.06 & 0.48 & 0.01 & 0.35 & 0.07 \\
\hline +8 SNR & 0.32 & 0.02 & 0.28 & 0.16 & 0.40 & 0.04 & 0.27 & 0.18 \\
\hline
\end{tabular}

comparison between both groups showed significant higher scores in the control group at different SNRs. This indicated that noise has more effect on children with SLI. Hearing in noise requires more attention, and speech cues used to understand speech are reduced in this situation. Generally, speech recognition is accompanied by a combination of acoustic, linguistic, semantic, and circumstantial cues. These redundant cues are used by the listener according to the communication context and situation [24].

The effect of noise was more pronounced on children with SLI than control group. Similar results were found by several authors (e.g., $[15,25])$. They reported poor scores of SLI group and poor speech tasks in background noise. Al-Assy et al. [26] reported lower scores of PSI test with ipsilateral competing message (ICM) that was poorer than contralateral competing message (CCM) in SLI children compared to normal.

Children with SLI are generally inefficient in processing the information underlying speech identification, and the condition is exacerbated by the presence of background noise. Both the peripheral and central auditory systems encode acoustic information sufficiently well as regard the envelope, periodicity, fine structure, and spectral cues in addition to intact masking release and intact temporal, and spectral auditory capacities [27, 28]. However, the central auditory system is inefficient at mapping acoustic information onto phonetic features to achieve normal recognition [27]. Delayed maturation of auditory closure, impaired attention, and impaired binaural separation are additional factors contributing to abnormal encoding of speech in those children [15]. Ziegler and Goswami [28] reported that temporal resolution is required to follow the background fluctuations and to extract speech cues from the background noise, whereas spectral resolution is required to access parts of the speech spectrum that are not or less masked by the background noise.

There was a positive correlation between different SNRs of PSI and expressive language age score indicating that as the age of the child increase the better the 
language age. This may reflect pronounced central auditory affection which improved with increasing age [26].

\section{Conclusion}

In conclusion, the present study points to an important connection between SLI and speech perception deficits particularly in the presence of background noise. Those children have abnormal encoding for specific acoustic features, reduction in synchronous neural firing to transient changes in speech, and impaired neural encoding of the duration and offset of a stimulus. This abnormality was manifested as abnormal PSI test results. So, it is recommended that PSI recording in the presence of noise should be part of the battery used for not only evaluating such impairment but for follow up after rehabilitation.

\section{Abbreviations}

ANOVA: Analysis of variance; CCM: Contralateral competing message; ICM: Ipsilateral competing message; IQ: Intelligence quotient; PLS: Preschool language scale; PSI: Pediatric Speech Intelligibility; PTA: Pure tone audiometry; SLI: Specific language impairment; SNR: Signal-to-noise ratio; SRT: Speech reception thresholds; WD\%: Word discrimination scores

\section{Acknowledgements}

The authors acknowledge that this work is original and represents honest work with no conflict of interest.

\section{Authors' contributions}

Authors of the work contributed as follows: THE: design, analysis, interpretation of data, scientific writing, and revision. TAG: design, data acquisition, analysis, interpretation of data, scientific writing, and revision. MED: data acquisition, statistical analysis, scientific writing. FMS: data acquisition, statistical analysis, scientific writing. Authors of this work had approved the submitted version and had agreed both to be personally accountable for the author's own contributions and ensure that questions related to the accuracy or integrity of any part of the work are appropriately investigated, resolved, and the resolution documented in the literature. The authors have read and approved the manuscript.

\section{Funding}

No funding

\section{Availability of data and materials}

All data and material of this work are available.

\section{Declarations}

\section{Ethics approval and consent to participate}

This work was approved by the Scientific Research Ethical Committee of Faculty of Medicine, Tanta University. Approval code 30166/3/31. Verbal consents were taken from the parents of all children who participated in this work which was accepted by the Ethical committee. The procedure was explained to all participants before getting their approvals.

\section{Consent for publication}

Not applicable.

\section{Competing interests}

The authors declare that they have no competing interests.

\section{Author details}

${ }^{1}$ Audiovestibular Unit, Otolaryngology Head and Neck Surgery Department, Tanta University Hospitals, Tanta, Egypt. ${ }^{2}$ Audiovestibular Unit, Otolaryngology Head and Neck Surgery Department, Kafrelsheikh University Hospitals, El-Geish street, Kafrelsheikh 33516, Egypt. ${ }^{3}$ Phoniatrics Unit, Otolaryngology Head and Neck Surgery Department, Tanta University Hospitals, Tanta, Egypt.
Received: 16 November 2020 Accepted: 6 May 2021

Published online: 20 May 2021

\section{References}

1. Glogowska M, Roulstone S, Peters T, Enderby P (2006) Early speech- and language-impaired children: linguistic, literacy, and social outcomes. Dev Med Child Neurol 6:489-494

2. Grimm A, Schulz P (2014) Specific language impairment and early second language acquisition: the risk of over- and underdiagnosis. Child Indic Res 7(4):821-841. https://doi.org/10.1007/s12187-013-9230-6

3. Bishop D, North T, Donlan C (1995) Genetic basis of specific language impairments. Evidence from twin study. Dev Med Child Neurol 137:56-71

4. Goronzy S, Rapp S, Kompe R (2004) Generating non-native pronunciation variants for lexicon adaptation. Speech Comm 42(1):109-123

5. Tomblin B, Records L, Zhang X (1996) A system for the diagnosis of specific language impairment in kindergarten children. J Speech Hear Res 39(6): 1284-1294. https://doi.org/10.1044/jshr.3906.1284

6. Webster Rl, Shevell M (2004) Neurobiology of specific language impairment. J Child Neurol I19(7):471-481

7. Erickson LC, Zielinski BA, Zielinski JE, Liu G, Turkeltaub PE, Leaver AM et al (2014) Distinct cortical locations for integration of audiovisual speech and the McGurk effect. Front Psychol 5:534

8. Farmer ME, Klein R (1993) Auditory and visual temporal processing in dyslexic and normal readers. Ann N Y Acad Sci 682:339-341

9. Prelock PA, Hutchins T, Glascoe FP (2008) Speech-language impairment: how to identify the most common and least diagnosed disability of childhood. Medscape J Med 10(6):136

10. Abu Hassiba A, El-Sady S, El-Shobary A (2011) Standardization, translation, and modification of preschool language scale [Unpublished MD Thesis]. Cairo

11. Faraj S (2010) Arabic translation of the Stanford-Binet Intelligence scales (SB5), 5th edn. The Angelo Egyptian Bookshop, Cairo

12. Soliman S, Tawfik S, Shalaby A (1995) Development and standardization of Arabic test battery for children. Proceeding of XXIII world congress of the international association of Logopedics and Phoniatrics, pp 416-419

13. Roid H (2003) Stanford Binet intelligence scales, 5th edn. Riverside Publishing, Itasca

14. Dockrell J, Lindsay G (2000) Meeting the needs of children with specific speech and language difficulties. Eur J Spec Educ Needs 15(1):24-41. https://doi.org/10.1080/088562500361682

15. EL-Amergy L, Tawfik S, Elsady S (2014) Psychophysical and electrophysiological assessment of central auditory processing in children with specific language impairment [Unpublished thesis]. Cairo

16. Bishop D, McArthur M (2004) Immature cortical responses to auditory stimuli in specific language impairment: evidence from ERPs to rapid tone sequences. Dev Sci 7(4):F11-F18. https://doi.org/10.1111/j.1467-7687.2004.00356.x

17. Rice ML (2016) Specific language impairment, nonverbal IQ, attentiondeficit/hyperactivity disorder, autism spectrum disorder, cochlear implants, bilingualism, and dialectal variants: defining the boundaries, clarifying clinical conditions, and sorting out causes. J Speech Lang Hear Res 59(1): 122-132. https://doi.org/10.1044/2015_JSLHR-L-15-0255

18. Evans JL, Brown TT (2015) Specific language impairment. In: Small SL, Hickok $\mathrm{G}$ (eds) TextBook of neurobiology of language. Academic press, San Diego, pp 899-912

19. Gabr T, Hassaan M (2015) Speech processing in children with cochlear implant. Int J Pediatr Otorhinolaryngol 79(12):2028-2034. https://doi.org/10.1 016/j.ijporl.2015.09.002

20. Hanna M, Abdel Hady A, Hosni N (2016) Speech auditory evoked brain stem response in children with specific language impairment [Unpublished thesis] Cairo

21. Dale PS, Simonoff E, Bishop DVM, Eley TC, Oliver B, Price TS et al (1988) Genetic influence on language delay in two-year-old children. Nat Neurosci 1(4):324-328

22. Wright BA, Lombardino LJ, King WM, Puranik CS, Leonard CM, Merzenich MM (1997) Deficits in auditory temporal and spectral resolution in language-impaired children. Nature 387:176-178

23. Kuchar J, Junqueira CMC (2010) Speech intelligibility with and without noise in individuals exposed to electronic music. Br J Otorhinolaryngol 6(3):280286

24. Lewis D, Schmid K, O'Leary S, Spalding J, Heinrichs-Graham E, Robin High R (2016) Effects of noise on speech recognition and listening effort in children 
with normal hearing and children with mild bilateral or unilateral hearing loss. J Speech Lang Hear Res 59(5):1218-1232

25. Zaiton H, Kamal N, Hazza N (2003) Measurement of central auditory abilities in primary school children with scholastic achievement [Unpublished thesis] Cairo

26. Al-Assy A, Tawfik, S, Ahmed, A (2005) Arabic pediatric speech intelligibility test in children with specific language impairment [Unpublished thesis] Cairo

27. Fallon M, Trehub SE, Schneider BA (2000) Children's perception of speech in multitalker babble. J Acoust Soc Am 108(6):3023-3029. https://doi.org/1 $0.1121 / 1.1323233$

28. Ziegler JC, Goswami U (2005) Reading acquisition, developmental dyslexia, and skilled reading across languages: a psycholinguistic grain size theory. Psychol Bull 131(1):3-29

\section{Publisher's Note}

Springer Nature remains neutral with regard to jurisdictional claims in published maps and institutional affiliations.

\section{Submit your manuscript to a SpringerOpen ${ }^{\circ}$ journal and benefit from:}

- Convenient online submission

- Rigorous peer review

- Open access: articles freely available online

High visibility within the field

- Retaining the copyright to your article

Submit your next manuscript at $\boldsymbol{\nabla}$ springeropen.com 